\title{
Relationship among bats, parasitic bat flies, and associated pathogens in Korea
}

\author{
Haeseung Lee', Min-Goo Seo ${ }^{2}$, Seung-Hun Lee ${ }^{3}$, Jae-Ku Oem', Seon-Hee Kim5, Hyesung Jeong ${ }^{5}$, \\ Yongkwan Kim ${ }^{5}$, Weon-Hwa Jheong ${ }^{5}$, Oh-Deog Kwon ${ }^{1}$ and Dongmi Kwak ${ }^{1 *}{ }^{5}$
}

\begin{abstract}
Background: Bats are hosts for many ectoparasites and act as reservoirs for several infectious agents, some of which exhibit zoonotic potential. Here, species of bats and bat flies were identified and screened for microorganisms that could be mediated by bat flies.
\end{abstract}

Methods: Bat species were identified on the basis of their morphological characteristics. Bat flies associated with bat species were initially morphologically identified and further identified at the genus level by analyzing the cytochrome c oxidase subunit I gene. Different vector-borne pathogens and endosymbionts were screened using PCR to assess all possible relationships among bats, parasitic bat flies, and their associated organisms.

Results: Seventy-four bat flies were collected from 198 bats; 66 of these belonged to Nycteribiidae and eight to Streblidae families. All Streblidae bat flies were hosted by Rhinolophus ferrumequinum, known as the most common Korean bat. Among the 74 tested bat flies, PCR and nucleotide sequencing data showed that 35 (47.3\%) and 20 (27.0\%) carried Wolbachia and Bartonella bacteria, respectively, whereas tests for Anaplasma, Borrelia, Hepatozoon, Babesia, Theileria, and Coxiella were negative. Phylogenetic analysis revealed that Wolbachia endosymbionts belonged to two different supergroups, A and F. One sequence of Bartonella was identical to that of Bartonella isolated from Taiwanese bats.

Conclusions: The vectorial role of bat flies should be checked by testing the same pathogen and bacterial organisms by collecting blood from host bats. This study is of great interest in the fields of disease ecology and public health owing to the bats' potential to transmit pathogens to humans and/or livestock.

Keywords: Bat, Bat fly, Blood-borne pathogen, Phylogeny, Prevalence

\section{Background}

As a group, bats include approximately 1432 species [1]. Several bat species are key to their ecosystems and also act as pathogen reservoirs [2]. Bat viruses are of great interest in disease ecology and public health owing to their potential to infect humans and livestock [3]. Moreover, bacteria and protozoa have also been detected in bats. Bartonella bacteria and Trypanosoma cruzi

\footnotetext{
*Correspondence: dmkwak@knu.ac.kr

${ }^{1}$ College of Veterinary Medicine, Kyungpook National University, 80 Daehak-ro, Buk-gu, Daegu 41566, South Korea

Full list of author information is available at the end of the article
}

protozoa, which are associated with bats, have also been detected in humans, making these bat-related organisms an urgent public health concern $[4,5]$. Bats harbor several ectoparasites, including bat flies, fleas, and certain arachnids, such as mites and ticks. Bat fly families Nycteribiidae and Streblidae belong to the superfamily Hippoboscoidea, which also includes the families Hippoboscidae (louse flies and keds) and Glossinidae (tsetse flies), and are the most common bat ectoparasites $[2,6]$.

Currently, 275 species of 21 genera of nycteribiids and 227 species of 31 genera of streblids have been described [7]. The importance of louse flies as a potential vector has been well studied. Recently, it has been confirmed original author(s) and the source, provide a link to the Creative Commons licence, and indicate if changes were made. The images or other third party material in this article are included in the article's Creative Commons licence, unless indicated otherwise in a credit line to the material. If material is not included in the article's Creative Commons licence and your intended use is not permitted by statutory regulation or exceeds the permitted use, you will need to obtain permission directly from the copyright holder. To view a copy of this licence, visit http://creativecommons.org/licenses/by/4.0/. The Creative Commons Public Domain Dedication waiver (http://creativeco mmons.org/publicdomain/zero/1.0/) applies to the data made available in this article, unless otherwise stated in a credit line to the data. 
that Anaplasma ovis, Bartonella spp., Rickettsia spp., and Trypanosoma spp. are present in these insects [8-10]. Bat flies are also considered vectors. In recent studies, bat ectoparasite burden was found to be proportional to Bartonella infection; moreover, Bartonella spp. were also detected in bat flies and host bats, underscoring the parasite vector potential. However, more research is warranted [11, 12]. Furthermore, it has not been demonstrated that bat flies transmit Bartonella bacteria. The vector potential of bat flies was demonstrated only in Polychromophilus spp. [13].

Bat flies are obligate ectoparasites for bats and include endosymbiotic prokaryotes that are not yet well understood; however, it is assumed that they establish a symbiotic relationship with mutualistic bacteria [14]. Members of the superfamily Hippoboscoidea require milk secretion for larval development, and certain bacteria such as Bartonella and Wolbachia can be vertically transmitted during this process. These bacteria can also be horizontally transmitted through parasitoids or via contact with contaminated saliva $[15,16]$. However, horizontal transmission has not been proven in bat flies or any other hippoboscids.

Wolbachia is a bacterium belonging to the order Rickettsiales, which includes the genera Anaplasma, Ehrlichia, and Rickettsia. Wolbachia influences host reproduction through extensive symbiotic interactions in some species and is estimated to be present in up to $66 \%$ of insect species [17]. Wolbachia has become an integral component of vector-mediated disease control due to its ability to spread through insect populations and influence vector competence through pathogen protection [18]. Bartonella spp. are parasitic bacteria that infect the red blood cells of vertebrates. Several different bacterial species [19], including Bartonella mayotimonensis, are associated with bats, some of which are zoonotic and can cause disease in humans [5].

However, to date, few studies have examined the pathogenic relationships among bat flies, although previous studies reported the possibility of Bartonella and Wolbachia bacteria occurring transiently [20, 21]. In general, the high degree of host specificity in bat flies reduces the likelihood of interspecies transmission of pathogens, but bat flies are still likely to carry transmissible pathogens within the host population [7]. Most previous studies on microorganisms, including those on Wolbachia spp., in bat flies have focused on endosymbiotic characteristics or distribution $[2,20]$.

In Korea, many vector-mediated diseases and causative agents, including Anaplasma, Bartonella, and Borrelia, occur in humans [22-24]. However, there are few data regarding bats and bat flies in Korea. Furthermore, a recent Korea-focused study assessed the local distribution of bat flies without considering the pathogens mediated by these flies [25]. Therefore, the purpose of this study was to investigate the relationships among bats, parasitic bat flies, and their associated bacteria in Korea.

\section{Methods}

\section{Study area, sample collection, and species identification of bats and bat flies}

Bats and bat flies were collected from caves, forests, and abandoned mines in 12 cities across seven provinces [Gangwon (Inje), Chungbuk (Danyang), Gyeongbuk (Yeongju, Andong, Yeongcheon, and Gyeongju), Ulsan, Jeonbuk (Sunchang), Gwangju, and Jeonnam (Muan, Jindo, and Wando)] of Korea from February 2016 to August 2017 (Fig. 1). A total of 198 dead bats were found, and 74 bat flies were collected and immersed in $70 \%$ ethyl alcohol solution. The bat flies were collected by ecologists licensed from the National Institute of Environmental Research, Korea. The bat species were identified based on their morphological characteristics as previously described [26, 27], and all collection-related information was provided from the ecologists.

Bat fly species were initially identified using key morphological characteristics, such as the presence or absence of wings, using a dissecting microscope (Fig. 2) [28]. The species were further identified at least at the genus level by analyzing the cytochrome c oxidase subunit I (COI) gene (approximately 658 bp length) [29, 30], which was amplified through PCR using invertebratespecific primers [31, 32].

\section{DNA extraction and PCR assay}

Bat fly DNA was extracted using the DNeasy ${ }^{\circledR}$ Blood \& Tissue Kit (Qiagen, Hilden, Germany) as per the manufacturer's instructions. An Infinite ${ }^{\circledR} 200$ PRO NanoQuant (Tecan, Männedorf, Switzerland) plate reader was used to assess the quality and quantity of bat fly DNA by calculating the ratio of the absorbance at $260 \mathrm{~nm}$ and $280 \mathrm{~nm}$. DNA samples were stored at $-20^{\circ} \mathrm{C}$ until further use.

The commercially available AccuPower ${ }^{\circledR}$ HotStart PCR Premix kit (Bioneer, Daejon, Korea) was used for PCR. This premix product includes most of the elements required for PCR, including DNA polymerase, dNTPs, reaction buffer, and metal ions, lyophilized in a single tube. For PCR amplification, primers, DNA template, and distilled water are added until the total volume of the mixture reaches $20 \mu \mathrm{l}$. Bat fly-mediated pathogens and bacterial organisms were detected by amplification using primers specific to a target gene in each microorganisms. All reactions were performed using $20 \mu \mathrm{l}$ reaction mixture containing $16 \mu \mathrm{l}$ distilled water, $1 \mu \mathrm{l}$ of $10 \mu \mathrm{M}$ of each primer pair, and $2 \mu \mathrm{l}$ template DNA. 


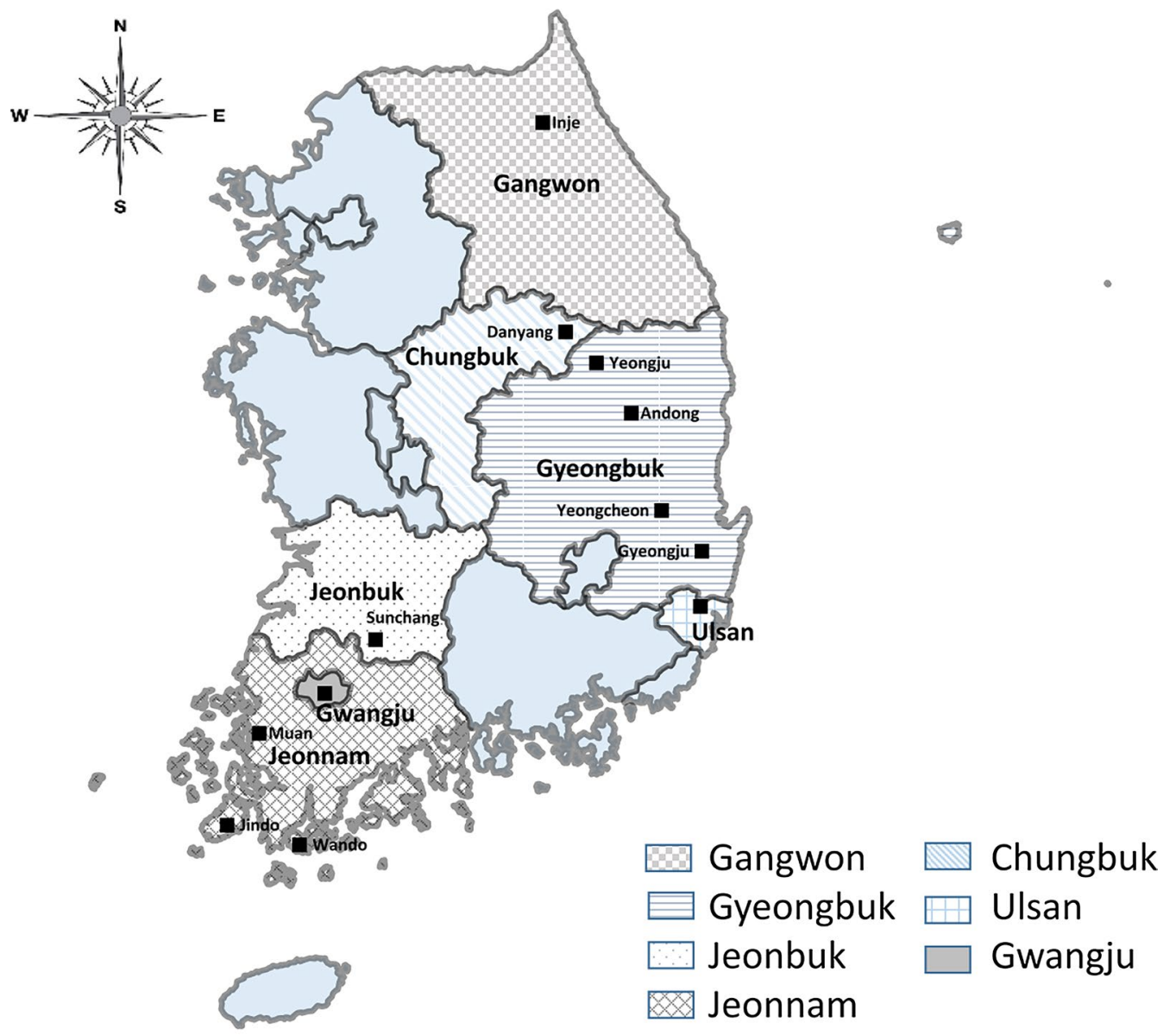

$100 \mathrm{~km}$

Fig. 1 Map of South Korea. Bats and bat flies were collected from regions marked with squares

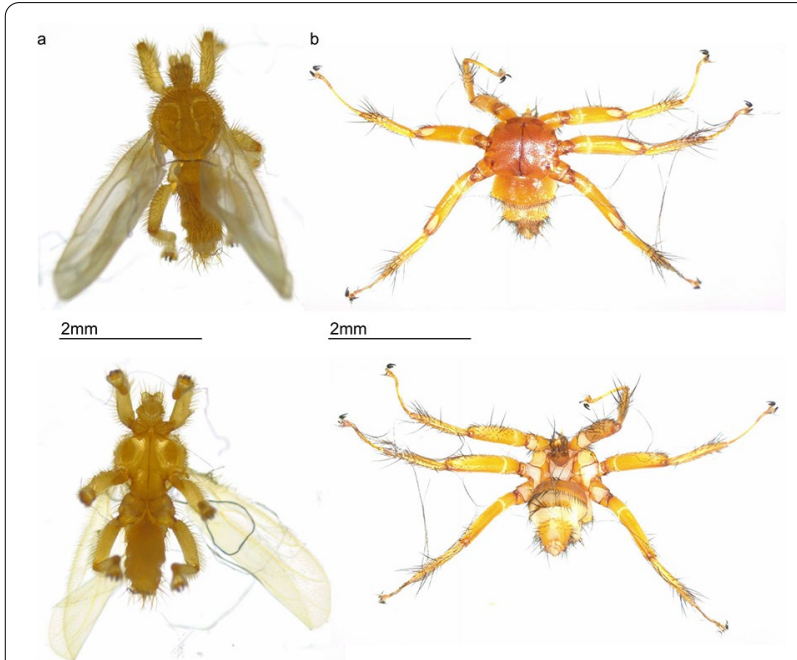

Fig. 2 Typical morphology of bat files belonging to the family a Streblidae and $\mathbf{b}$ Nycteribiidae. Note the existence or absence of wings. Upper, dorsal view; lower, ventral view
We amplified the 16S rRNA regions of Rickettsiales (Anaplasma, Ehlrichia, Rickettsia, and Wolbachia species) and Coxiella spp; 5S-23S rRNA regions of Borrelia spp.; 18S rRNA regions of Babesia, Theileria, and Hepatozoon species; and internal transcribed spacer I (ITS-1) regions of Bartonella spp. [23, 33-36]. Positive DNA samples were confirmed using a second set of PCR primers to amplify other regions of the gene, including citrate synthase gene ( $\mathrm{glt} A$ ) of Bartonella spp. [37] and cell division protein FtsZ (ftsZ) of Wolbachia spp. [36]. These primers are listed in Additional file 1: Table S1, along with their expected amplicon sizes. All PCR amplifications were performed using the Mastercycler $^{\circledR}$ nexus GSX1 (Eppendorf, Hamburg, Germany) under conditions outlined in Additional file 2: Table S2. The PCR products were electrophoresed on a $1 \%$ agarose gel stained with ethidium bromide. All amplicons were visualized and photographed using a UV transilluminator, and PCR-positive products were sent 
to Macrogen (Daejeon, Korea) for DNA sequencing analysis.

\section{Sequencing and phylogenetic analysis}

The obtained sequence data were aligned and edited using BioEdit 7.2.5 [38]. MEGA 7 was used to construct phylogenetic trees for each species using the maximum likelihood method with 1000 replicates based on the fragments of COI, ftsZ, and gltA of bat flies, Wolbachia spp., and Bartonella spp., respectively [39]. Reference sequence data were obtained using NCBI Web BLAST (http://www.ncbi.nlm.nih.gov/blast). The phylogenetic tree of Wolbachia spp. based on ftsZ was constructed using 27 GenBank database entries and Ehrlichia sp. as the outgroup. The phylogenetic tree of the Bartonella spp. based on gltA was constructed using 15 GenBank database entries and Brucella sp. as the outgroup.

\section{Results}

\section{Identification of bat species}

Overall, 11 species of seven genera belonging to three families were morphologically identified from 198 bats. One species each of Miniopteridae and Rhinolophidae and nine species of Vespertilionidae were found. The most common bat species was Miniopterus fuliginosus (32.8\%, $n=65)$, followed by Rhinolophus ferrumequinum (29.3\%, $n=58)$, Myotis macrodactylus $(14.1 \%, n=28)$, Vespertilio sinensis $(7.1 \%, n=14)$, Myotis petax $(4.0 \%$, $n=8)$, Eptesicus serotinus (3.5\%, $n=7)$, Myotis bombinus $(3.0 \%, n=6)$, Murina hilgendorfi (2.5\%, $n=5)$, Hypsugo alaschanicus $(1.5 \%, n=3)$, Myotis ikonnikovi (1.0\%, $n=2)$, Myotis aurascens $(0.5 \%, n=1)$, and one unidentified specimen (Table 1).

\section{Identification of bat fly species}

A total of 74 bat flies were collected from 198 bats. Ectoparasites other than bat flies were not detected. Organisms belonging to the families Nycteribiidae $(89.2 \%, n=66)$ and Streblidae $(10.8 \%, n=8)$ were identified in three species of host bat (Table 2). Among the Nycteribiidae specimens, five species from three genera were identified, and the \% similarities of the bat fly species based on their GenBank match were as follows: Nycteribia allotopa (100\% with LC522000), Nycteribia parvula (96.7\% with KF021501), Nycteribia pleuralis (94.3\% with AB632553), Penicillidia jenynsii (98.6\% with AB632562), and Phthiridium hindlei (99.9\% with AB632569). Among the Streblidae specimens, only one species of the genus Brachytarsina was identified, and \% similarity of the bat fly species based on GenBank match was Brachytarsina kanoi (93.0\% with AB632571) (Fig. 3; Table 2). Although it is the closest homology to this species, there is the probability of another closely related species apart from this. Most bat fly specimens were found on $M$. fuliginosus $(51.4 \%, n=38)$. All P. hindlei $(n=15)$ and Brachytarsina sp. $(n=8)$ were parasitic on the bat species $R$. ferrumequinum. Most $P$. jenynsii (family Nycteribiidae) flies were collected from the specimens obtained from the Jeonbuk Province (24/26), whereas only two such individuals were identified in specimens from the Chungbuk Province. Brachytarsina sp. (family Streblidae) was identified in three specimens from

Table 1 Bat distribution by location

\begin{tabular}{|c|c|c|c|c|c|c|c|c|c|c|}
\hline & Bat species $(n)$ & Chungbuk & Gangwon & Gwangju & Gyeongbuk & Jeonnam & Jeonbuk & Ulsan & Unknown & $\%$ \\
\hline \multicolumn{11}{|c|}{ Miniopteridae (65) } \\
\hline Miniopterus & Miniopterus fuliginosus (65) & 16 & & & 7 & 1 & 39 & & 2 & 32.8 \\
\hline \multicolumn{11}{|c|}{ Rhinolophidae (58) } \\
\hline Rhinolophus & Rhinolophus ferrumequinum (58) & 4 & & 4 & 6 & 8 & 9 & 12 & 15 & 29.3 \\
\hline \multicolumn{11}{|c|}{ Vespertilionidae (74) } \\
\hline Eptesicus & Eptesicus serotinus (7) & & & 3 & 4 & & & & & 3.5 \\
\hline Hypsugo & Hypsugo alaschanicus (3) & 2 & & & & & & & 1 & 1.5 \\
\hline Murina & Murina hilgendorfi (5) & & & & & & & & 5 & 2.5 \\
\hline \multirow[t]{5}{*}{ Myotis } & Myotis aurascens (1) & 1 & & & & & & & & 0.5 \\
\hline & Myotis bombinus (6) & & & & 6 & & & & & 3.0 \\
\hline & Myotis ikonnikovi (2) & & 2 & & & & & & & 1.0 \\
\hline & Myotis macrodactylus (28) & 3 & & & & 2 & 20 & & 3 & 14.1 \\
\hline & Myotis petax (8) & 6 & & & 2 & & & & & 4.0 \\
\hline \multirow[t]{2}{*}{ Vespertilio } & Vespertilio sinensis (14) & 10 & & & & & & & 4 & 7.1 \\
\hline & Unidentified (1) & & & & 1 & & & & & 0.5 \\
\hline Total & (198) & 42 & 2 & 7 & 26 & 11 & 68 & 12 & 30 & 100 \\
\hline
\end{tabular}


Table 2 Collected host bat and bat fly species identification

\begin{tabular}{|c|c|c|c|c|c|c|c|c|c|}
\hline \multirow{3}{*}{$\begin{array}{l}\text { Host bat } \\
\text { species }\end{array}$} & \multicolumn{8}{|c|}{ No. of collected bat fly (\%) } & \multirow[t]{3}{*}{ Total } \\
\hline & \multicolumn{7}{|c|}{$\begin{array}{l}\text { Nycteribiidae } \\
(66,89.2 \%)\end{array}$} & \multirow{2}{*}{$\begin{array}{l}\text { Streblidae } \\
(8,10.8 \%) \\
\text { Brachytarsina } \\
\text { sp. }^{c}\end{array}$} & \\
\hline & $\begin{array}{l}\text { Nycteribia } \\
\text { allotopa }\end{array}$ & $\begin{array}{l}\text { Nycteribia } \\
\text { parvula }\end{array}$ & Nycteribia sp. ${ }^{a}$ & Nycteribia sp. ${ }^{b}$ & $\begin{array}{l}\text { Penicillidia } \\
\text { jenynsii }\end{array}$ & $\begin{array}{l}\text { Phthiridium } \\
\text { hindlei }\end{array}$ & Unidentified & & \\
\hline $\begin{array}{l}\text { Miniopterus } \\
\text { fuliginosus }\end{array}$ & $2(2.7)$ & $2(2.7)$ & $2(2.7)$ & $2(2.7)$ & $22(29.7)$ & $0(0.0)$ & $8(10.8)$ & $0(0.0)$ & $38(51.4)$ \\
\hline $\begin{array}{l}\text { Myotis macro- } \\
\text { dactylus }\end{array}$ & $0(0.0)$ & $0(0.0)$ & $3(4.1)$ & $0(0.0)$ & $3(4.1)$ & $0(0.0)$ & $0(0.0)$ & $0(0.0)$ & $6(8.1)$ \\
\hline $\begin{array}{l}\text { Rhinolophus } \\
\text { ferrumequi- } \\
\text { num }\end{array}$ & $0(0.0)$ & $0(0.0)$ & $1(1.4)$ & $0(0.0)$ & $1(1.4)$ & $15(20.3)$ & $5(6.8)$ & $8(10.8)$ & $30(40.5)$ \\
\hline Total & $2(2.7)$ & $2(2.7)$ & $6(8.1)$ & $2(2.7)$ & $26(35.1)$ & $15(20.3)$ & $13(17.6)$ & $8(10.8)$ & $74(100.0)$ \\
\hline
\end{tabular}

${ }^{a}$ The closest GenBank matching species is Nycteribia pleuralis

${ }^{\mathrm{b}}$ The closest GenBank matching species is not identified

${ }^{\text {CT } T h e ~ c l o s e s t ~ G e n B a n k ~ m a t c h i n g ~ s p e c i e s ~ i s ~ B r a c h y t a r s i n a ~ k a n o i ~}$

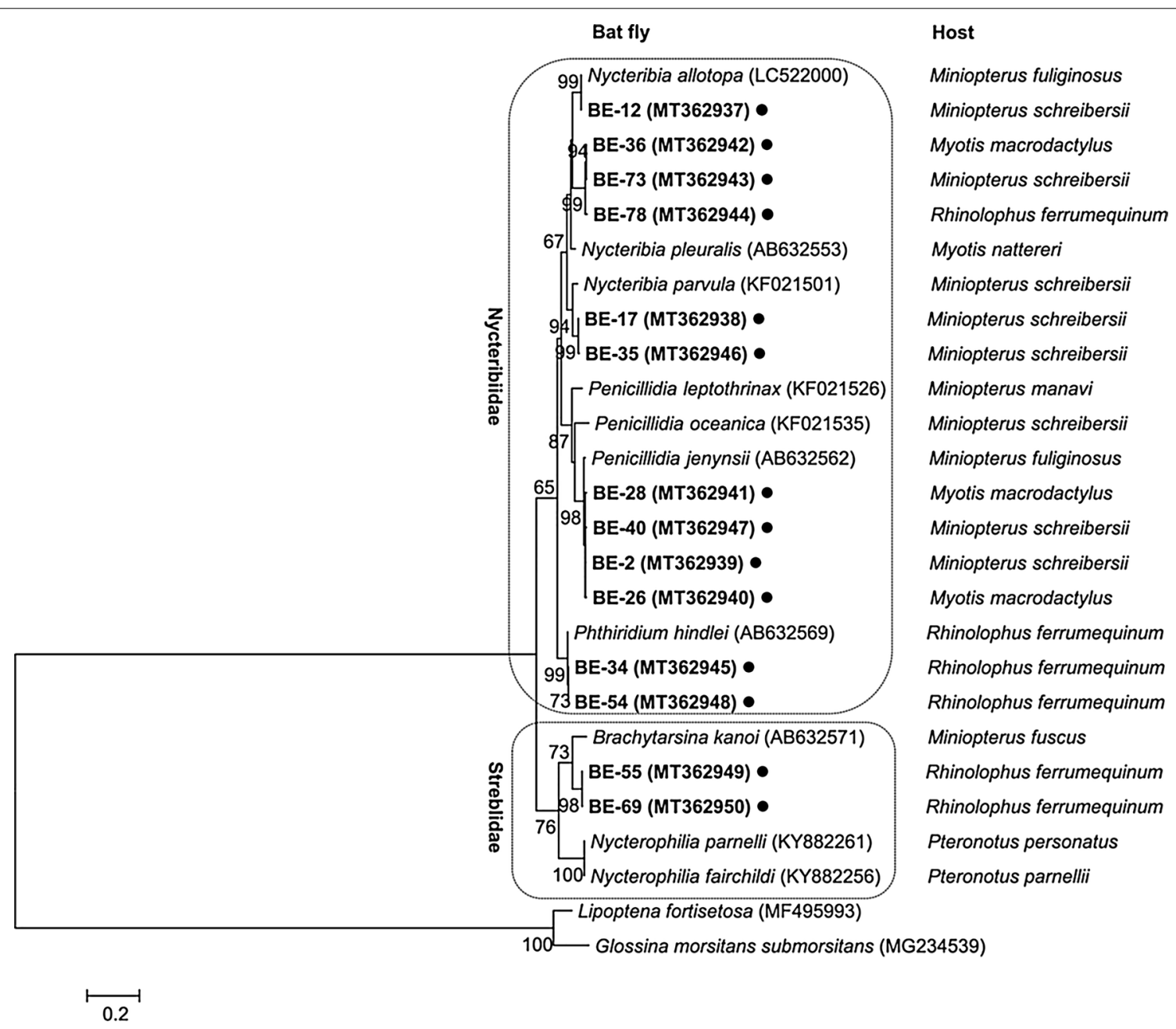

Fig. 3 Phylogenetic tree based on bat fly cytochrome c oxidase subunit I gene-amplifying sequences. The ked and tsetse fly sequences were used as outgroups. Scale bar indicates an evolutionary distance of 0.20 nucleotides per position in the sequence. The black circles (0) indicate the bat fly sequences identified in this study 
Gyeongbuk, three specimens from Jeonnam, and two specimens from Ulsan (Table 3).

\section{Screening for pathogens and endosymbionts mediated by bat flies}

Of the identified pathogens and endosymbionts, 35 specimens were part of the Wolbachia spp. (47.3\%) and 20 specimens of the Bartonella spp. (27.0\%); no other microorganisms (such as Coxiella, Borrelia, Anaplasma, Ehlrichia, Rickettsia, Hepatozoon, Babesia, and Theileria species) were detected. Most Wolbachia spp. were detected in P. jenynsii (22/35, 64.7\%), and Bartonella spp. were most frequently found in $P$. hindlei $(10 / 20,50.0 \%)$ (Table 4).

\section{Sequence and phylogenetic analyses of bat fly-mediated pathogens and endosymbionts}

Wolbachia spp. in P. hindlei share 97.7-99.8\% sequence identity with Wolbachia-hosting spiders, moths, and beetles (GenBank: KT319069, FM883705, KC578235). Wolbachia spp. in $N$. parvula and P. jenynsii share 95.4-98.5\% sequence identity with Wolbachia spp. isolated from cockroach and termite (GenBank: AJ292345, FJ390318, DQ457402) and 95.0-96.7\% sequence identity with that isolated from nematode (GenBank: FR827926, AJ628414).

Through phylogenetic analysis of the Wolbachia spp., the three sequences from Phthiridium spp. bat flies were clustered as supergroup A, and the other two sequences from Nycteribia spp. and Penicillidia spp. bat flies were clustered as supergroup F (Fig. 4) [17].

In the phylogenetic analysis of Bartonella gltA amplified from the bat flies in this study, six representative sequences were obtained from five bat fly species with $86.6-91.9 \%$ sequence identity (Fig. 5). Bartonella sequences from the bat fly $P$. hindlei (GenBank: MT362935) presented $91.9 \%$ identity with $P$. jenynsii (GenBank: MT362933), 91.7\% with N. allotopa (GenBank: MT362931), and 86.6\% with Nycteribia sp. (GenBank: MT362934). Particularly, one Bartonella sequence detected from the Japanese bat fly (GenBank: LC522030) had $100 \%$ sequence identities with the Bartonella sequences from this study (GenBank: MT362932 and MT362933). In addition, Bartonella sequences from the Taiwan bat (GenBank: JF500511), Japanese bat (GenBank: LC483820), and bat fly (GenBank: LC522032) had $100 \%$ sequence identity with a Bartonella sequence detected in this study (GenBank: MT362931).

\section{Discussion}

According to the morphological characteristics of bats identified in Korea, 24 species have been reported from 11 genera [26, 27]. According to the key to the order Chiroptera in Korea, four bat families (Miniopteridae, Molossidae, Rhinolophidae, and Vespertilionidae) have been reported in Korea. In this study, 11 species

Table 3 Bat fly distribution by location ${ }^{a}$

\begin{tabular}{|c|c|c|c|c|c|c|c|}
\hline Bat fly species & Bat host species $(n)$ & Chungbuk & Gyeongbuk & Jeonbuk & Jeonnam & Ulsan & Unknown \\
\hline \multicolumn{8}{|l|}{ Nycteribiidae (66) } \\
\hline Nycteribia allotopa (2) & Miniopterus fuliginosus (2) & 1 & & 1 & & & \\
\hline Nycteribia parvula (2) & Miniopterus fuliginosus (2) & 1 & & 1 & & & \\
\hline \multirow[t]{3}{*}{ Nycteribia sp. ${ }^{b}(6)$} & Miniopterus fuliginosus (2) & 1 & & 1 & & & \\
\hline & Myotis macrodactylus (3) & 1 & & 2 & & & \\
\hline & Rhinolophus ferrumequinum (1) & & & 1 & & & \\
\hline Nycteribia sp.' (2) & Miniopterus fuliginosus (2) & & & 2 & & & \\
\hline \multirow[t]{3}{*}{ Penicillidia jenynsii (26) } & Miniopterus fuliginosus (22) & 2 & & 20 & & & \\
\hline & Myotis macrodactylus (3) & & & 3 & & & \\
\hline & Rhinolophus ferrumequinum (1) & & & 1 & & & \\
\hline Phthiridium hindlei (15) & Rhinolophus ferrumequinum (15) & 3 & 3 & & 3 & 5 & 1 \\
\hline \multirow[t]{2}{*}{ Unidentified (13) } & Rhinolophus ferrumequinum (5) & & & 3 & 2 & & \\
\hline & Miniopterus fuliginosus (8) & 5 & & 3 & & & \\
\hline \multicolumn{8}{|l|}{ Streblidae (8) } \\
\hline Brachytarsina sp. $^{\mathrm{d}}(8)$ & Rhinolophus ferrumequinum (8) & & 3 & & 3 & 2 & \\
\hline Total (74) & & 14 & 6 & 38 & 8 & 7 & 1 \\
\hline
\end{tabular}

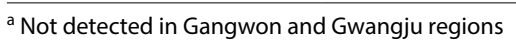

${ }^{b}$ The closest GenBank matching species is Nycteribia pleuralis

'The closest GenBank matching species is not identified

${ }^{d}$ The closest GenBank matching species is Brachytarsina kanoi 
Table 4 Distribution of endosymbionts detected in bat flies

\begin{tabular}{|c|c|c|c|}
\hline Bat fly species & Bat host species (n) & Wolbachia & Bartonella \\
\hline \multicolumn{4}{|l|}{ Nycteribiidae } \\
\hline Nycteribia allotopa (2) & Miniopterus fuliginosus (2) & 0 & 1 \\
\hline Nycteribia parvula (2) & Miniopterus fuliginosus (2) & 2 & 0 \\
\hline \multirow[t]{3}{*}{ Nycteribia sp. ${ }^{a}(6)$} & Miniopterus fuliginosus (2) & 0 & 1 \\
\hline & Myotis macrodactylus (3) & 0 & 1 \\
\hline & Rhinolophus ferrumequinum (1) & 0 & 0 \\
\hline Nycteribia sp. ${ }^{b}(2)$ & Miniopterus fuliginosus (2) & 0 & 0 \\
\hline \multirow[t]{3}{*}{ Penicillidia jenynsii (26) } & Miniopterus fuliginosus (22) & 20 & 3 \\
\hline & Myotis macrodactylus (3) & 2 & 0 \\
\hline & Rhinolophus ferrumequinum (1) & 0 & 0 \\
\hline Phthiridium hindlei (15) & Rhinolophus ferrumequinum (15) & 10 & 10 \\
\hline \multirow[t]{2}{*}{ Unidentified (13) } & Rhinolophus ferrumequinum (5) & 1 & 1 \\
\hline & Miniopterus fuliginosus (8) & 0 & 1 \\
\hline Subtotal (66) & & $35(53.0)$ & $18(27.3)$ \\
\hline \multicolumn{4}{|l|}{ Streblidae } \\
\hline Brachytarsina sp. ${ }^{c}(8)$ & Rhinolophus ferrumequinum (8) & 0 & 2 \\
\hline Subtotal (8) & & $0(0.0)$ & $2(25.0)$ \\
\hline Total (74) & & $35(47.3)$ & $20(27.0)$ \\
\hline
\end{tabular}

${ }^{a}$ The closest GenBank matching species is Nycteribia pleuralis

${ }^{b}$ The closest GenBank matching species is not identified

'The closest GenBank matching species is Brachytarsina kanoi

belonging to seven genera in three families (Miniopteridae, Rhinolophidae, and Vespertilionidae) were identified. The collection places of bats were recorded for all except 31 specimens (these specimen data on tubes were erased because of leakage of ethanol during transfer), most of which were found in mines (79 specimens), caves (76 specimens), and the rest forests (12 specimens). Rhinolophus ferrumequinum was found in all regions except Gangwon; however, this does not necessarily mean that it does not occur in Gangwon. Only two bat specimens were collected from Gangwon. Rhinolophus ferrumequinum is known to be the most widely occurring bat in Korea [26].

A total of 74 bat flies were collected. One possible reason for this small number could be that the flies were collected from dead bats. Therefore, several bat flies would have left after the host bat died.

Molecular identification and phylogenies of bat flies have been widely utilized over the last decade to characterize different fly species $[40,41]$. COI, in particular, has been proven a useful marker in the documentation of invertebrates and insects [41-43]. Previous studies on Korean bat fly were limited to morphological characteristics [25]. Moreover, traditional morphological identification methods are extremely time-consuming because bat flies are complex, extremely small, and diverse in species. Although this does not justify the lack of morphology-based identification, our results showed that a molecular approach would be useful in the quick identification of the different species of bat flies, at least at the genus level. There was a limitation that $\mathrm{COI}$ was not sufficient to reliably identify bat flies by itself at the species level because sequence data of many species are still missing from the GenBank. Therefore, in this study, COI sequencing enabled genus-level identification and indicated the closest GenBank match species. In some species, the most similar GenBank sequences showed a similarity of $<95 \%$ (N. pleuralis, 94.3\%; B. kanoi, 93.0\%), whereas others showed a similarity of $>98 \%$ ( $N$. allotopa, 100\%; P. jenynsii, 98.6\%; P. hindlei, 99.9\%). Therefore, more comparable data on $\mathrm{COI}$ will allow a clear distinction of bat flies at the species level. Previously, $\mathrm{COI}$ was also used for species identification in other families of Diptera [44, 45].

Phthiridium hindlei is an ectoparasite of $R$. ferrumequinum, which has not been reported in Korea previously. Most Nycteribia spp. were detected in M. fuliginosus $(8 / 12,66.7 \%)$, which is consistent with the findings of a previous study that collected Nycteribia spp. from Miniopterus sp. in Korea [25].

Penicillidia jenynsii (family Nycteribiidae) was mostly collected from the Jeonbuk Province (24/26), with only two individuals identified in the Chungbuk Province. Brachytarsina sp. (family Streblidae) was confirmed only 


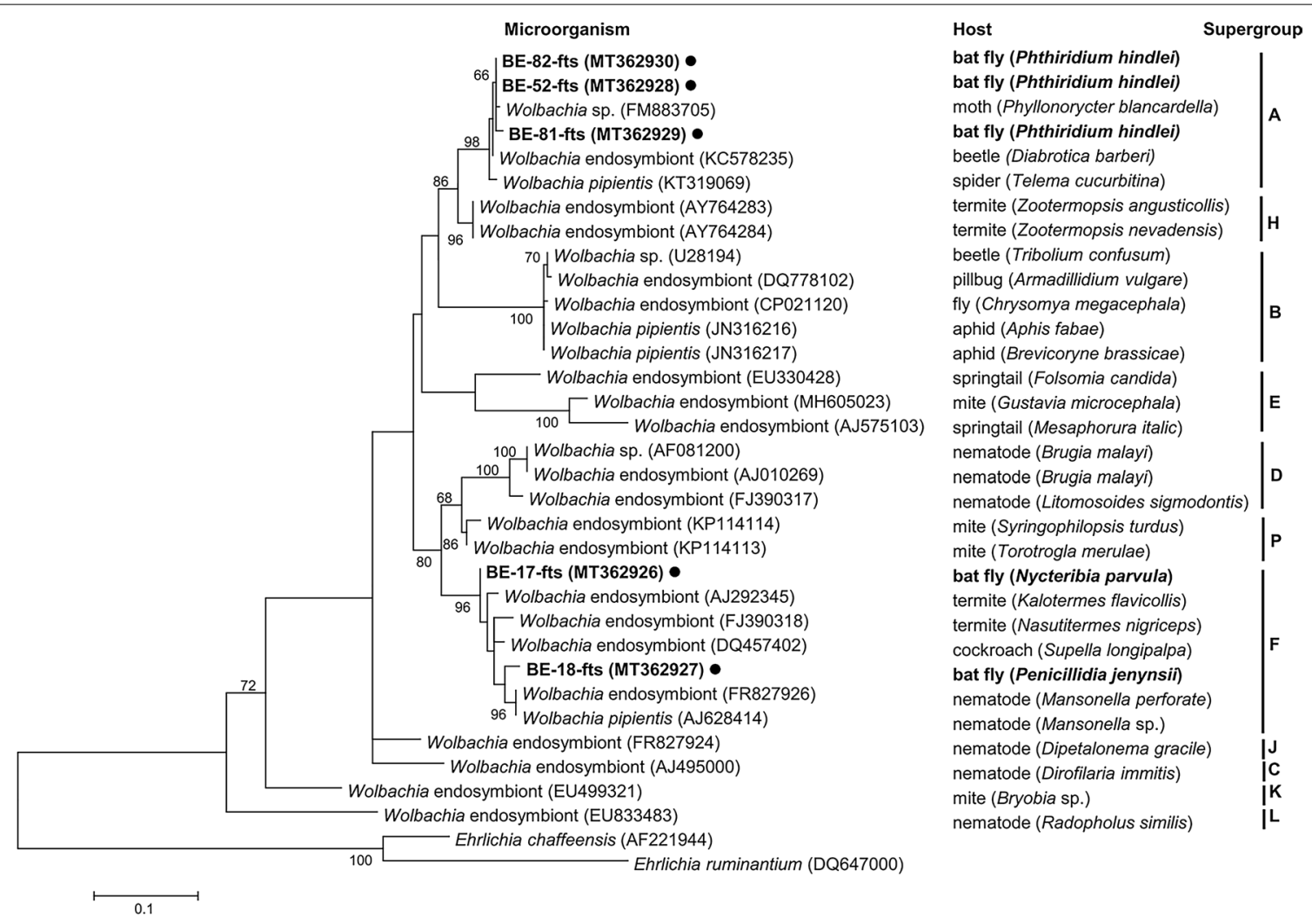

Fig. 4 A phylogenetic tree was constructed with Wolbachia ftsZ gene-amplifying sequences generated in this study using the maximum likelihood method based on the Tamura-Nei model (1000 replicates). Sequences identified in this study are marked with black circles (O) with isolated ID and host species scientific name. The Ehrlichia sequences were used as outgroup

in Jeonnam, Gyeongbuk, and Ulsan Provinces, but not in Jeonbuk and Chungbuk Provinces. However, because there is a history of discovery of Brachytarsina sp. in Jeju Island and Gangwon Province [25] in the southernmost and northernmost regions of Korea, respectively, more population studies on ectoparasites and identification are required.

This study confirmed the high prevalence of Wolbachia and Bartonella bacteria and that P. hindlei was highly coinfected with Wolbachia and Bartonella spp. (9/10). According to the identification results of these pathogens and endosymbionts in this study, Wolbachia spp. was identified at a rate of $53.0 \%(35 / 66)$ in the family Nycteribiidae [Penicillidia sp. (22/26, 84.6\%), Nycteribia spp. (2/12, 16.7\%), Phthiridium sp. $(10 / 15,66.7 \%)$ and an unidentified Nycteribiidae species (1/13, 7.7\%)] but not in the family Streblidae (Brachytarsina sp.). This is believed to be associated with the vertical transfer of the endosymbiont from mother to offspring through the mammary glands. Endosymbiont localization is consistently observed in all nycteribiid bat flies. In particular, $P$. jenynsii females exhibit a different pattern from that of males. In the abdominal cavity of females, larvae were found around the mammary glands, which supplied secretions and exhibited endosymbiont signals [20]. Bartonella spp. were identified at a rate of $27.3 \%(18 / 66)$ from the family Nycteribiidae [Phthiridium sp. (10/15, 60.7\%), Nycteribia spp. (3/12, 25.0\%), Penicillidia sp. (3/26, 11.5\%), and an unidentified Nycteribiidae species $(2 / 13,15.4 \%)]$ and at a rate of $25.0 \%(2 / 8)$ in the family Streblidae (Brachytarsina sp.).

A previous study reported that the most common microparasites in bat flies were bacteria $(n=149)$, with high numbers of Bartonella spp. $(n=91,61.0 \%)$ but few Wolbachia spp. $(n=8,5.4 \%)$ [2]. However, in this study, Wolbachia spp. were detected at a higher rate $(35 / 74$, 47.3\%), whereas Bartonella bacteria detection was less frequent $(20 / 74,27.0 \%)$. This could be due to the differences in sample collection time and areas.

As per the phylogeny results of Wolbachia and Bartonella bacteria, we confirmed that each species of bat flies clustered as separated roots of each type. The Wolbachia endosymbionts detected in our study were clustered into two supergroups, A and F. Supergroup A was found in arthropods, whereas supergroup $F$ was found in both filariae and arthropods [17]. All supergroup A 

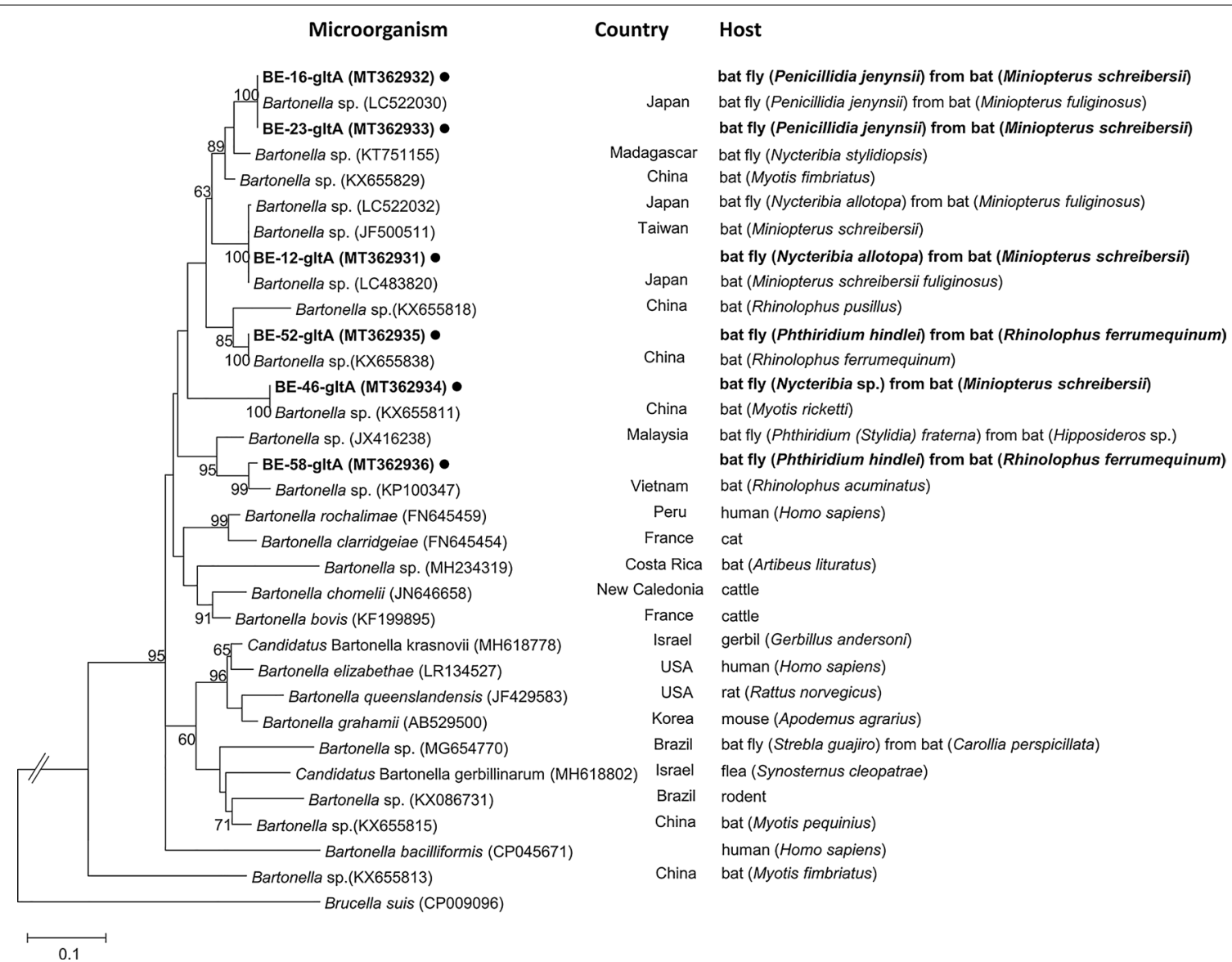

Fig. 5 A phylogenetic tree was constructed with the Bartonella gltA gene-amplifying sequences generated in this study using the maximum likelihood method based on the Tamura-Nei model (1000 replicates). Sequences identified in this study are indicated by black circles ( $)$ with isolated ID and host species scientific name. The Brucella sequences were used as outgroup

endosymbionts were detected in $P$. hindlei. Supergroup F endosymbionts were detected in other bat flies (Penicillidia sp. and Nycteribia spp.). The presence of Wolbachia spp. confirmed that various arthropods could be vectors, and the bat fly Wolbachia spp. could have sequences similar to both filariae and arthropods. In addition, the possibility of Wolbachia bacteria transmission through bat blood should be studied to determine the connection between bat flies and bats.

Bartonella endosymbionts were also grouped according to their bat fly host except $P$. hindlei. However, these sequences clustered into distinct Bartonella groups and were considered a separate Bartonella species because of its $<96 \%$ identity [46, 47]. Interestingly, in this study, with two separate branch groups, Bartonella host specificity in bats and bat flies was confirmed; one is $P$. jenynsii group and the other $N$. allotopa group, all of which had Miniopterus sp. bat hosts. In a previous study conducted in northern China, bat and Bartonella host specificity was recorded [48], and it was suggested that $N$. allotopa is the vector for transmitting Bartonella in bats [49]. However, the correlation between Bartonella species originating from bats and other bat fly species (another Nycteribia sp. and $P$. hindlei) requires further study.

Bartonella bacterial infection has been reported in humans and animals in African countries, where it was observed that a large number of local bat flies were positive for Bartonella spp. [50]. Bat ectoparasites generally exhibit high host specificity; therefore, their impact on other animal species and humans may be low, but the spread of bat-borne Bartonella spp. poses a global risk $[29,51]$. Furthermore, it must be considered that endosymbionts of bat flies may come from their bat hosts. Recent research suggests that bat flies transfer viruses to host bats as well as humans [7]. Nycteribiids are known to host several Bartonella spp., and bat and Bartonella bacteria associations have been studied in several parts of the world, including Asia [30]. In this study, our data indicated that Wolbachia and Bartonella bacteria are associated with bat fly species. In 
this regard, studies on bat fly-mediated pathogens and endosymbionts are of great public health significance and require continued interest and research.

\section{Conclusions}

This study employed morphological and molecular techniques to identify bat fly species in Korea. We also determined the distribution of $P$. hindlei and its endosymbionts. Using molecular methods, we identified several microorganisms, such as the endosymbiotic Wolbachia and possibly pathogenic or endosymbiotic Bartonella of bat flies, that are parasites for Korean bats. This is the first study to use such methods to identify Korean bat flies. Although the possibility of pathogen transmission through direct contact with a bat fly is low, subsequent studies on bat blood are required to confirm the potential for direct infection between bats and bat flies. This is an important public health concern owing to its potential for transmission to other species through bats.

\section{Abbreviations}

COI: Cytochrome c oxidase subunit I; ITS-1: Internal transcribed spacer I.

\section{Supplementary Information}

The online version contains supplementary material available at https://doi. org/10.1186/s13071-021-05016-6.

Additional file 1: Table S1. Primers used for species identification of bat flies and pathogen detection in bat flies.

Additional file 2: Table S2. PCR conditions.

\section{Acknowledgements}

Not applicable.

\section{Authors' contributions}

All authors have seen and approved the manuscript. $\mathrm{HL}$ and DK did experimental concept design and wrote the manuscript. HL, MGS, SHL, JKO, SHK, HJ, YK, WHJ, ODK, and DK provided experimental data analysis and reviewed the manuscript. All authors read and approved the final manuscript.

\section{Funding}

This work was partially supported by grants from the National Institute of Environmental Research (grant number NIER-2019-01-01-006) in the Ministry of Environment, Korea, and from the Basic Science Research Program through the National Research Foundation of Korea funded by the Ministry of Education (grant number NRF-2016R1D1A1B02015366). The funder had no role in study design, data collection and analysis, decision to publish, or preparation of the manuscript.

\section{Availability of data and materials}

Data supporting the conclusions of this article are included within the article. The newly generated sequences were submitted to the GenBank database under the accession numbers: MT362937-MT362950 (COl:), MT362926MT362930 (ftsZ), and MT362931-MT362936 (g/tA). The datasets used and/ or analyzed during the present study are available from the corresponding author upon reasonable request.

\section{Declarations}

\section{Ethics approval and consent to participate}

The bat flies used in this study were collected under the supervision of the National Institute of Environmental Research and the Ministry of the Environment in Korea. The collected bat flies were attached to the bodies of dead bats in caves, forests, and abandoned mines. Bat fly collection was performed by ecologists as permitted by the Ministry of Environment in Korea for the purpose of disease monitoring.

\section{Consent for publication}

Not applicable.

\section{Competing interests}

The authors declare that they have no competing interests.

\section{Author details}

${ }^{1}$ College of Veterinary Medicine, Kyungpook National University, 80 Daehak-ro, Buk-gu, Daegu 41566, South Korea. ${ }^{2}$ Veterinary Drugs and Biologics Division, Animal and Plant Quarantine Agency, 177 Hyeoksin 8-ro, Gimcheon, Gyeongbuk 39660, South Korea. ${ }^{3}$ College of Veterinary Medicine, Chungbuk National University, 1 Chungdae-ro, Seowon-gu, Cheongju, Chungbuk 28644, South Korea. ${ }^{4}$ College of Veterinary Medicine, Jeonbuk National University, 79 Gobong-ro, Iksan, Jeonbuk 54596, South Korea. ${ }^{5}$ National Institute of Wildlife Disease Control and Prevention, 1 Songam-gil, Gwangsan-gu, Gwangju 62407, South Korea.

Received: 4 February 2021 Accepted: 14 September 2021

Published online: 27 September 2021

\section{References}

1. Simmons, N.B. and A.L. Cirranello. 2020. Bat Species of the World: A taxonomic and geographic database. Accessed 28 June 2021.

2. Szentivanyi T, Christe P, Glaizot O. Bat flies and their microparasites: current knowledge and distribution. Front Vet Sci. 2019;6:115.

3. Dobson AP. What links bats to emerging infectious diseases? Science. 2005;310:628-9.

4. Ramirez JD, Hernandez C, Montilla M, Zambrano P, Florez AC, Parra E, et al. First report of human Trypanosoma cruzi infection attributed to TcBat genotype. Zoonoses Public Health. 2014;61:477-9.

5. Veikkolainen V, Vesterinen EJ, Lilley TM, Pulliainen AT. Bats as reservoir hosts of human bacterial pathogen, Bartonella mayotimonensis. Emerg Infect Dis. 2014;20:960-7.

6. Reeves WK, Lloyd JE. Chapter 20-louse flies, keds, and bat flies (Hippoboscoidea). In: Mullen GR, Durden LA, editors. Medical and veterinary entomology. 3rd ed. Cambridge: Academic Press; 2019. p. 421-38.

7. Dick CW, Patterson BD. Bat flies: obligate ectoparasites of bats. In: Morand S, Krasnov B, Poulin R, editors. Micromammals and macroparasites. Tokyo: Springer; 2006. p. 179-94.

8. Bose R, Petersen K. Lipoptena cervi (Diptera), a potential vector of Megatrypanum trypanosomes of deer (Cervidae). Parasitol Res. 1991;77:723-5.

9. Dehio C, Sauder U, Hiestand R. Isolation of Bartonella schoenbuchensis from Lipoptena cervi, a blood-sucking arthropod causing deer ked dermatitis. J Clin Microbiol. 2004;42:5320-3.

10. Hornok S, de la Fuente J, Biro N, Fernandez de Mera IG, Meli ML, Elek V, , et al. First molecular evidence of Anaplasma ovis and Rickettsia spp. in keds (Diptera: Hippoboscidae) of sheep and wild ruminants. Vector Borne Zoonotic Dis. 2011;11:1319-21.

11. Brook CE, Bai Y, Dobson AP, Osikowicz LM, Ranaivoson HC, Zhu QY, et al. Bartonella spp in fruit bats and blood-feeding ectoparasites in Madagascar. PLoS Negl Trop Dis. 2015;9:e0003532.

12. Stuckey MJ, Chomel BB, Galvez-Romero G, Olave-Leyva J, ObregonMorales C, Moreno-Sandoval H, et al. Bartonella infection in hematophagous, insectivorous, and phytophagous bat populations of Central Mexico and the Yucatan Peninsula. Am J Trop Med Hyg. 2017;97:413-22.

13. Gardner RA, Molyneux DH. Polychromophilus murinus: a malarial parasite of bats: life-history and ultrastructural studies. Parasitology. 1988;96:591-605. 
14. Morse SF, Bush SE, Patterson BD, Dick CW, Gruwell ME, Dittmar K. Evolution, multiple acquisition, and localization of endosymbionts in bat flies (Diptera: Hippoboscoidea: Streblidae and Nycteribiidae). Appl Environ Microbiol. 2013;79:2952-61.

15. de Bruin A, van Leeuwen AD, Jahfari S, Takken W, Foldvari M, Dremmel L et al. Vertical transmission of Bartonella schoenbuchensis in Lipoptena cervi. Parasit Vectors. 2015;8:176

16. Heath BD, Butcher RDJ, Whitfield WGF, Hubbard SF. Horizontal transfer of Wolbachia between phylogenetically distant insect species by a naturally occurring mechanism. Curr Biol. 1999;9:313-6.

17. Landmann F. The Wolbachia endosymbionts. Microbiol Spectr. 2019;7:BAI-0018-2019.

18. Slatko BE, Luck AN, Dobson SL, Foster JM. Wolbachia endosymbionts and human disease control. Mol Biochem Parasitol. 2014;195:88-95.

19. Jiyipong T, Jittapalapong S, Morand S, Raoult D, Rolain JM. Prevalence and genetic diversity of Bartonella spp. in small mammals from Southeastern Asia. Appl Environ Microbiol. 2012;78:8463-6.

20. Hosokawa T, Nikoh N, Koga R, Sato M, Tanahashi M, Meng XY, et al. Reductive genome evolution, host-symbiont co-speciation and uterine transmission of endosymbiotic bacteria in bat flies. ISME J. 2012:6:577-87.

21. Reeves WK, Loftis AD, Gore JA, Dasch GA. Molecular evidence for novel bartonella species in Trichobius major (Diptera: Streblidae) and Cimex adjunctus (Hemiptera: Cimicidae) from two southeastern bat caves, USA. J Vector Ecol. 2005;30:339-41.

22. Kim KH, Yi J, Oh WS, Kim NH, Choi SJ, Choe PG, et al. Human granulocytic anaplasmosis, South Korea, 2013. Emerg Infect Dis. 2014;20:1708-11.

23. Ko S, Kim SJ, Kang JG, Won S, Lee H, Shin NS, et al. Molecular detection of Bartonella grahamii and B. schoenbuchensis-related species in Korean water deer (Hydropotes inermis argyropus). Vector Borne Zoonotic Dis. 2013;13:415-8.

24. Park KH, Chang WH, Schwan TG. Identification and characterization of Lyme disease spirochetes, Borrelia burgdorferi sensu lato, isolated in Korea. J Clin Microbiol. 1993;31:1831-7.

25. Kim HC, Han SH, Dick CW, Choi YG, Chong ST, Klein TA, et al. Geographical distribution of bat flies (Diptera: Nycteribiidae and Streblidae), including two new records, Nycteribia allotopa and N. formosana, collected from bats (Chiroptera: Rhinolophidae and Vespertilionidae) in the Republic of Korea. J Vector Ecol. 2012;37:333-7.

26. Jo YS, Baccus JT, Koprowski JL. Mammals of Korea. National Institute of Biological Resources; 2018.

27. Yoon MH. Vertebrate fauna of Korea, vol. 5, no. 1: Bats. National Institute of Biological Resources; 2010.

28. Szentivanyi T, Estok P, Foldvari M. Checklist of host associations of European bat flies (Diptera: Nycteribiidae, Streblidae). Zootaxa. 2016;4205:101-26.

29. Tortosa P, Dsouli N, Gomard Y, Ramasindrazana B, Dick CW, Goodman SM. Evolutionary history of Indian Ocean Nycteribiid bat flies mirroring the ecology of their hosts. PLos ONE. 2013;8:e75215.

30. Wilkinson DA, Duron O, Cordonin C, Gomard Y, Ramasindrazana B, Mavingui $P$, et al. The bacteriome of bat flies (Nycteribiidae) from the Malagasy region: a community shaped by host ecology, bacterial transmission mode, and host-vector specificity. Appl Environ Microbiol. 2016:82:1778-88.

31. Folmer O, Black M, Hoeh W, Lutz R, Vrijenhoek R. DNA primers for amplification of mitochondrial cytochrome c oxidase subunit I from diverse metazoan invertebrates. Mol Mar Biol Biotechnol. 1994;3:294-9.

32. Hornok S, Kontschan J, Kovats D, Kovacs R, Angyal D, Gorfol T, et al. Bat ticks revisited: Ixodes ariadnae sp. nov. and allopatric genotypes of I. vespertilionis in caves of Hungary. Parasit Vectors. 2014;7:202.

33. Duplan F, Davies S, Filler S, Abdullah S, Keyte S, Newbury H, et al. Anaplasma phagocytophilum, Bartonella spp., haemoplasma species and Hepatozoon spp. in ticks infesting cats: a large-scale survey. Parasit Vectors. 2018;11:201.

34. Duron $\mathrm{O}$, Jourdain $\mathrm{E}, \mathrm{McC}$ Cy KD. Diversity and global distribution of the Coxiella intracellular bacterium in seabird ticks. Ticks Tick Borne Dis. 2014:5:557-63.
35. Rar V, Livanova N, Tkachev S, Kaverina G, Tikunov A, Sabitova Y, et al. Detection and genetic characterization of a wide range of infectious agents in Ixodes pavlovskyi ticks in Western Siberia. Russia Parasit Vectors. 2017;10:258.

36. Sarwar MS, Jahan N, Shahbaz F. Molecular detection and characterization of Wolbachia pipientis from Culex quinquefasciatus collected from Lahore, Pakistan. Am J Trop Med Hyg. 2018;98:154-61.

37. Billeter SA, Hayman DT, Peel AJ, Baker K, Wood JL, Cunningham A, et al. Bartonella species in bat flies (Diptera: Nycteribiidae) from western Africa. Parasitology. 2012;139:324-9.

38. Hall TA. BioEdit: a user-friendly biological sequence alignment editor and analysis program for Windows 95/98/NT. Nucl Acids Symp Ser. 1999:41:95-8.

39. Kumar S, Stecher G, Tamura K. MEGA7: molecular evolutionary genetics analysis version 7.0 for bigger datasets. Mol Biol Evol. 2016;33:1870-4.

40. Obame-Nkoghe J, Rahola N, Bourgarel M, Yangari P, Prugnolle F, Maganga GD, et al. Bat flies (Diptera: Nycteribiidae and Streblidae) infesting cavedwelling bats in Gabon: diversity, dynamics and potential role in Polychromophilus melanipherus transmission. Parasit Vectors. 2016;9:333.

41. Petersen FT, Meier R, Kutty SN, Wiegmann BM. The phylogeny and evolution of host choice in the Hippoboscoidea (Diptera) as reconstructed using four molecular markers. Mol Phylogenet Evol. 2007;45:111-22.

42. Vivero RJ, Torres-Gutierrez C, Bejarano EE, Pena HC, Estrada LG, Florez F, et al. Study on natural breeding sites of sand flies (Diptera: Phlebotominae) in areas of Leishmania transmission in Colombia. Parasit Vectors. 2015;8:116.

43. Zhang DX, Hewitt GM. Assessment of the universality and utility of a set of conserved mitochondrial COI primers in insects. Insect Mol Biol. 1997:6:143-50.

44. Gutierrez-Lopez R, Martinez-de la Puente J, Gangoso L, Soriguer RC, Figuerola J. Comparison of manual and semi-automatic DNA extraction protocols for the barcoding characterization of hematophagous louse flies (Diptera: Hippoboscidae). J Vector Ecol. 2015;40:11-5.

45. Park SH, Zhang Y, Piao H, Yu DH, Jeong HJ, Yoo GY, et al. Use of cytochrome c oxidase subunit I (COI) nucleotide sequences for identification of the Korean Luciliinae fly species (Diptera: Calliphoridae) in forensic investigations. J Korean Med Sci. 2009;24:1058-63.

46. La Scola B, Zeaiter Z, Khamis A, Raoult D. Gene-sequence-based criteria for species definition in bacteriology: the Bartonella paradigm. Trends Microbiol. 2003;11:318-21.

47. McKee CD, Kosoy MY, Bai Y, Osikowicz LM, Franka R, Gilbert AT, et al. Diversity and phylogenetic relationships among Bartonella strains from Thai bats. PLos ONE. 2017;12:e0181696.

48. Han HJ, Wen HL, Zhao L, Liu JW, Luo LM, Zhou CM, et al. Novel Bartonella species in insectivorous bats, Northern China. PLos ONE. 2017;12:e0167915.

49. Nabeshima K, Sato S, Kabeya H, Komine N, Nanashima R, Takano A, et al. Detection and phylogenetic analysis of Bartonella species from bat flies on eastern bent-wing bats (Miniopterus fuliginosus) in Japan. Comp Immunol Microbiol Infect Dis. 2020;73:101570.

50. Trataris AN, Rossouw J, Arntzen L, Karstaedt A, Frean J. Bartonella spp. in human and animal populations in Gauteng South Africa, 2007 to 2009. Onderstepoort J Vet. 2012;79:452.

51. Dietrich M, Tjale MA, Weyer J, Kearney T, Seamark ECJ, Nel LH, et al. Diversity of Bartonella and Rickettsia spp. in bats and their bloodfeeding ectoparasites from South Africa and Swaziland. PLos ONE. 2016;11:e0152077.

\section{Publisher's Note}

Springer Nature remains neutral with regard to jurisdictional claims in published maps and institutional affiliations. 